\title{
PERANCANGAN SISTEM INFORMASI PENDISTRIBUSIAN GULA TEBU PADA KELOMPOK TANI INGIN MAJU NAGARI BALINGKA
}

\author{
Febby Kesumaningtyas \\ Program Studi Manajemen Informatika \\ Akademi Manajemen Informatika \& Komputer ( AMIK ) Boekittinggi \\ Email : febbykesumaningtyas25@gmail.com
}

\begin{abstract}
Abstrak; Penelitian Sistem Informasi pendistribusian pada kelompok Tani Ingin Maju Balingka dengan menggunakan Bahasa Pemograman Berbasis Web dengan tujuan untuk merancang program informasi yang digunakan untuk memberikan kemudahan dalam proses pemesanan pada kelompok tani ingin maju.Metode penelitian yang digunakan dalam penelitian ini adalah : studi lapangan, yaitu dengan melakukan observasi dan wawancara, kemudian studi pustaka. Berdasarkan penelitian yang penulis lakukan pada Kelompok Tani Ingin Maju Kanagarian Balingka maka penulis dapat menarik kesimpulan yaitu : Dengan memanfaatkan sistem komputerisasi yang telah dibuat dapat membantu para anggota.
\end{abstract}

Kata Kunci : Perancancangan Sistem Informasi, Pendistribusian, Mysql, dan Bahasa Pemrograman Web.

Abstract: Distribution Information Research System for Farmers Want to Advance Balingka groups using Web-Based Programming Language with the aim to design information programs that are used to provide ease in the ordering process for farmer groups want to progress. The research methods used in this study are: field studies, namely by conducting observations and interviews, then literature study. Based on research by the author of the Farmers Group Want to Advance Kanagarian Balingka, the author can draw conclusions, namely: By utilizing a computerized system that has been made can help the members.

Keywords: Information System Design, Distribution, Mysql, and Web Programming Languages.

\section{PENDAHULUAN}

Seiring jalannya waktu pada era modern seperti pada saat ini teknologi merupakan peranan yang sangat penting dimana teknologi tersebut memperoleh kemudahan dalam aktifitas kehidupan, seperti halnya pada bidang teknologi komputer, dimana teknologi komputer merupakan salah satu alternatif yang dapat memenuhi kehidupan manusia untuk meningkatkan kualitas dan kuantitas kerja yang baik dalam instansi pemerintah maupun swasta. Dengan itu komputer merupakan perkembangan teknologi yang penting karena mempunyai kemampuan yang cepat dalam mengakses data dibanding dengan cara yang manual dan komputer juga dapat melakukan pencarian data secara cepat dan dengan hasil yang akurat, sehingga pekerjaan dapat dilakukan dengan efektif dan efisien baik dari segi waktu maupun tenaga.

Sementara kelompok Tani Ingin Maju Nagari Balingka adalah kelompok masyarakat yang mengelola Tebu menjadi Gula Tebu, yang mana sudah cukup lama berdiri. Pendistribusian gula tebu ini mencakup daerah bukittinggi dan sekitarnya pasar aur kuning, padang luar dan pasar Koto Baru. Disini penulis melihat sekilas usaha yang sudah lama berdiri ini belum menggunakan sistem komputerisasi, dan semua kegiatan disini masih dikerjakan secara manual seperti pencatatan pendistribusian gula tebu semua itu di catat dalam buku. 


\section{METODE PENELITIAN}

Lokasi penelitian sama dengan sumber data yang diperlihatkan, dimana penelitian secara langsung di kelompok tani ingin maju nagari balingka. Dalam penelitian ini metode yang digunakan yaitu metode pengumpulan data berupa jenis data dan sumber data tersebut.

\section{HASIL DAN PEMBAHASAN}

Use Case Diagram Baru

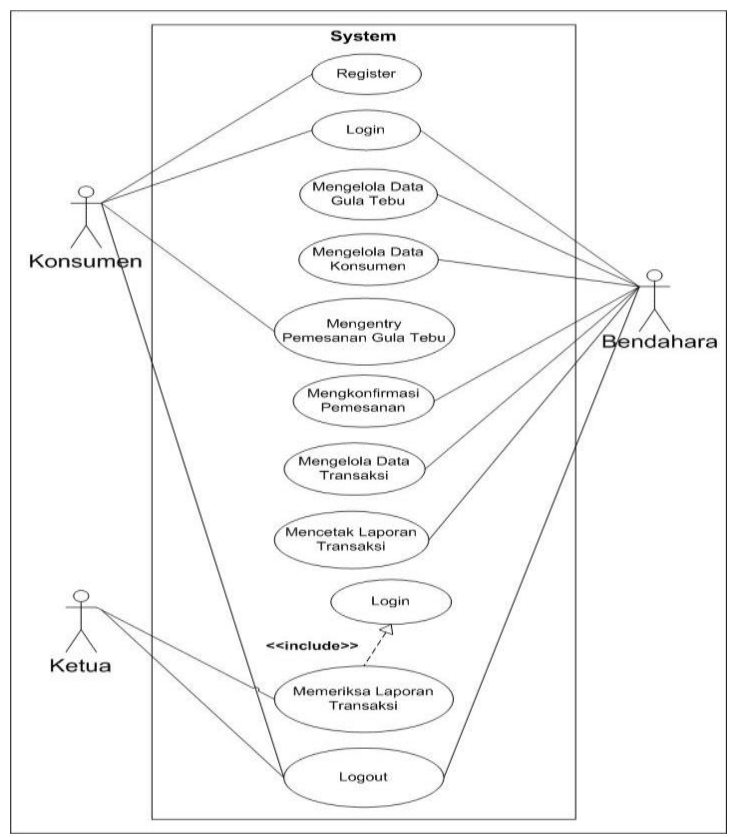

\section{Activity Diagram}

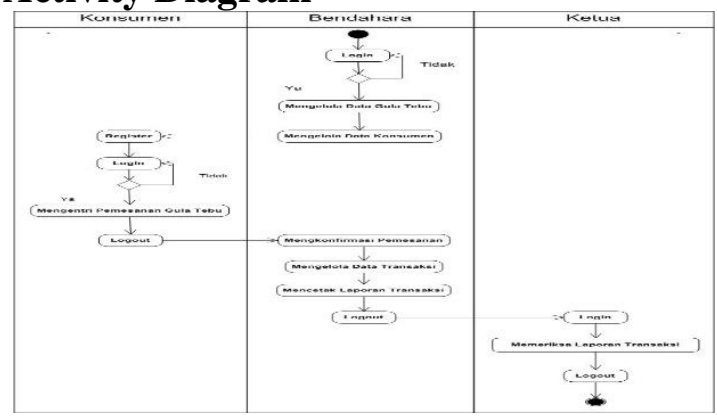

\section{Class Diagram}

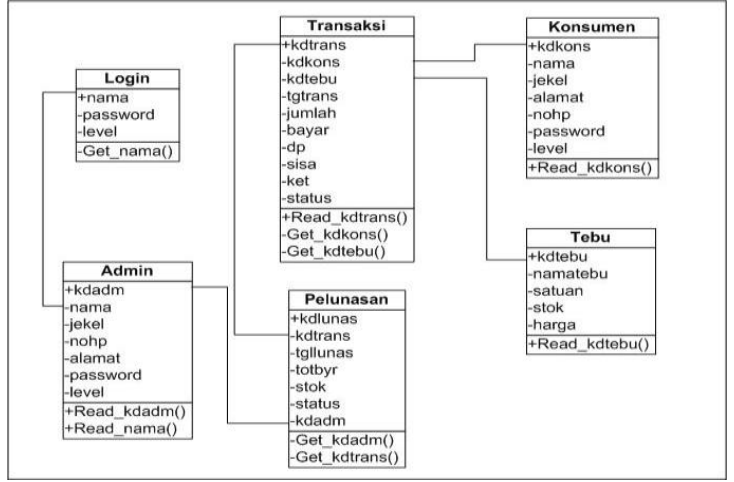

\section{Disain Input}

\section{Input Login}

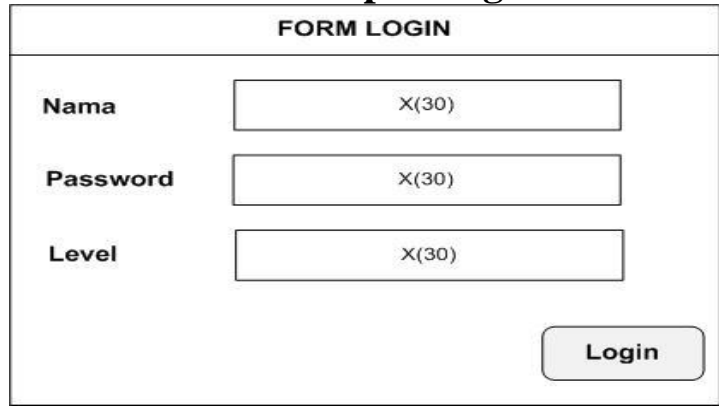

Gambar 1. Form Login

\section{Input Admin}

\begin{tabular}{|c|c|c|}
\hline \multicolumn{3}{|c|}{ FORM ADMIN } \\
\hline Kode Admin & & \\
\hline Nama & & \\
\hline Jenis Kelamin & & \\
\hline Alamat & & \\
\hline No. Hp & & \\
\hline Password & & \\
\hline Level & & \\
\hline Simpan & Edit & Delete \\
\hline
\end{tabular}

Gambar 2. Form Admin

3. Input Konsumen

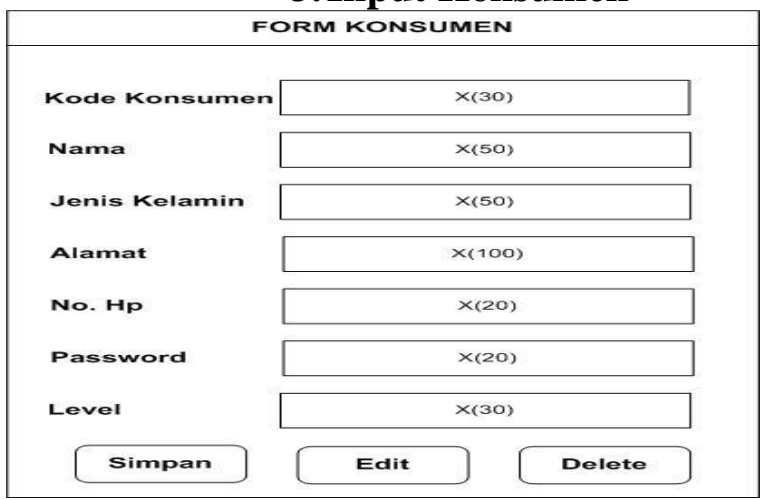

Gambar 3. Form Konsumen 


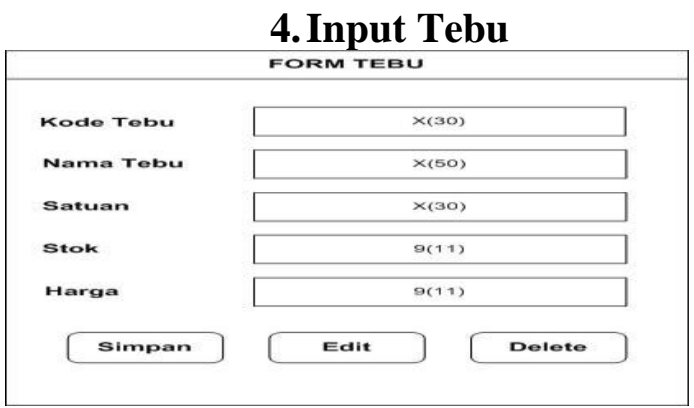

Gambar 4. Form Tebu

\section{Input Transaksi}

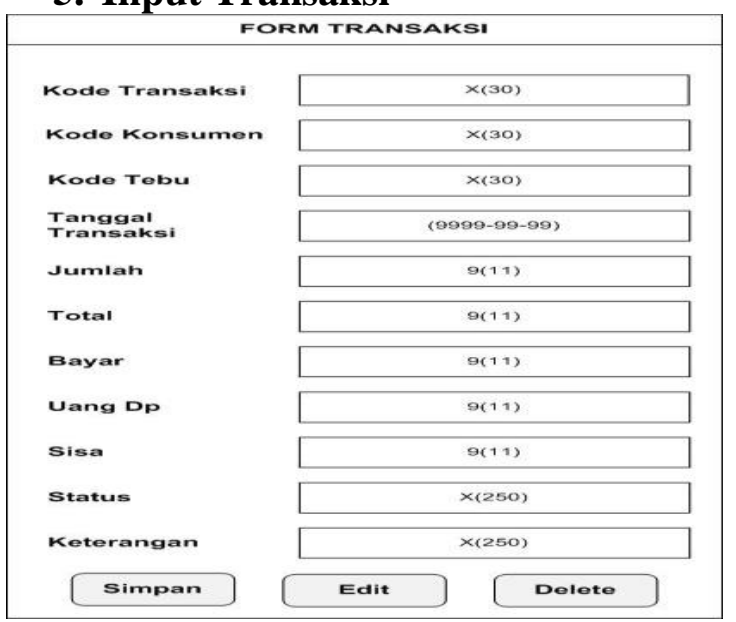

Gambar 5. Form Transaksi

6. Input Pelunasan

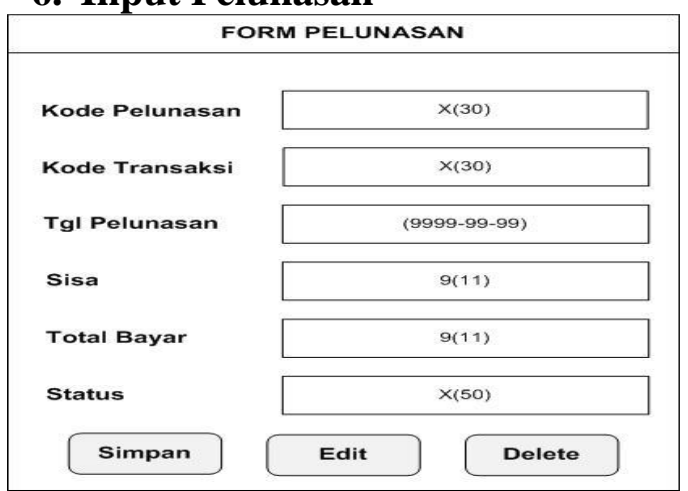

Gambar 6. Form Pelunasan

\section{Disain Output}

1. Laporan Konsumen

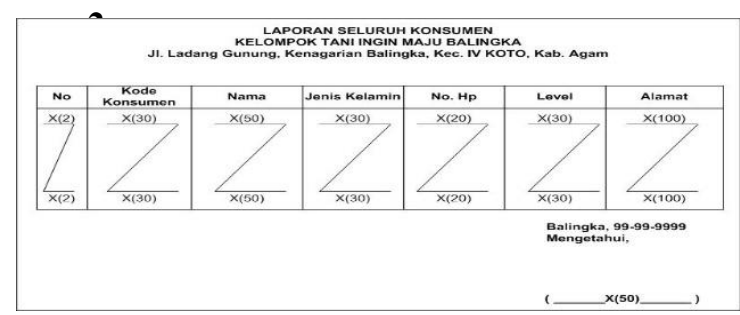

Gambar 7. Laporan Konsumen

\section{Laporan Tebu}

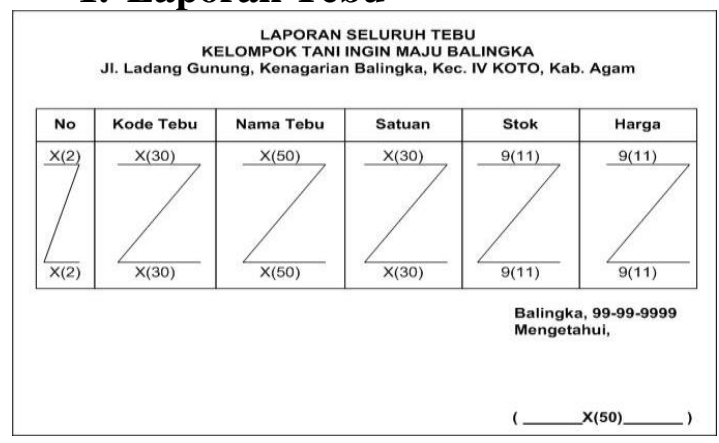

Gambar 8. Laporan Tebu

\section{Laporan Transaksi}

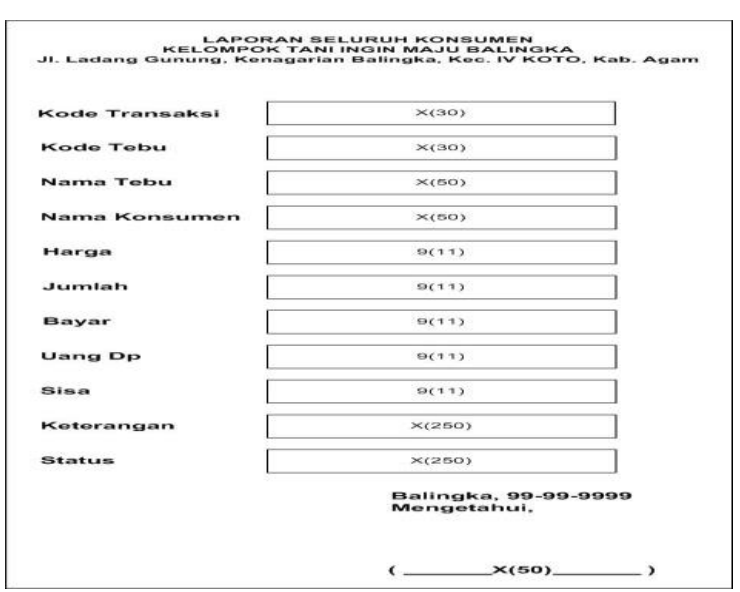

Gambar 9. Laporan Transaksi

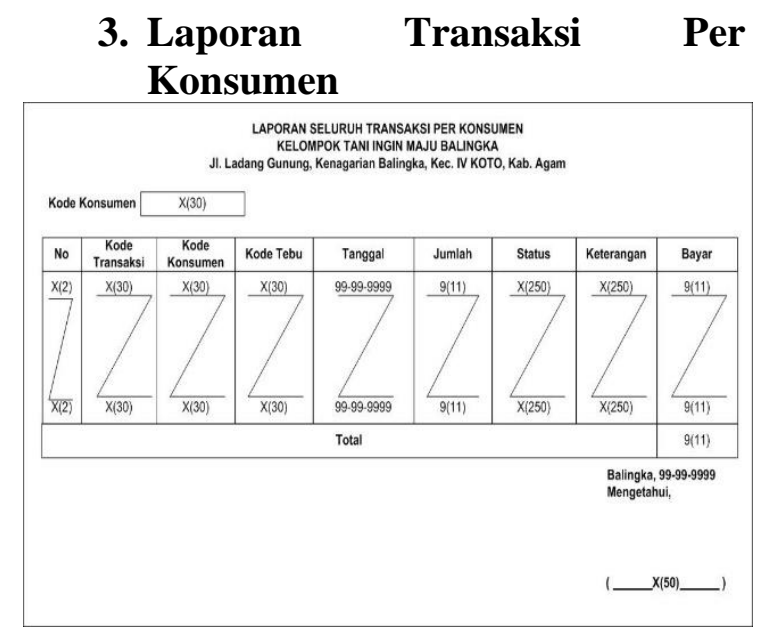

Gambar 10. Laporan Transaksi Per Konsumen 
4. Laporan Transaksi Per Tanggal

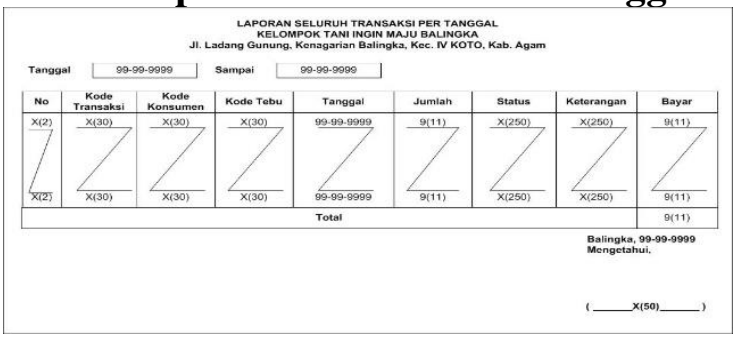

Gambar 11. Laporan Transaksi Per Tanggal

\section{Laporan Transaksi Per Bulan}

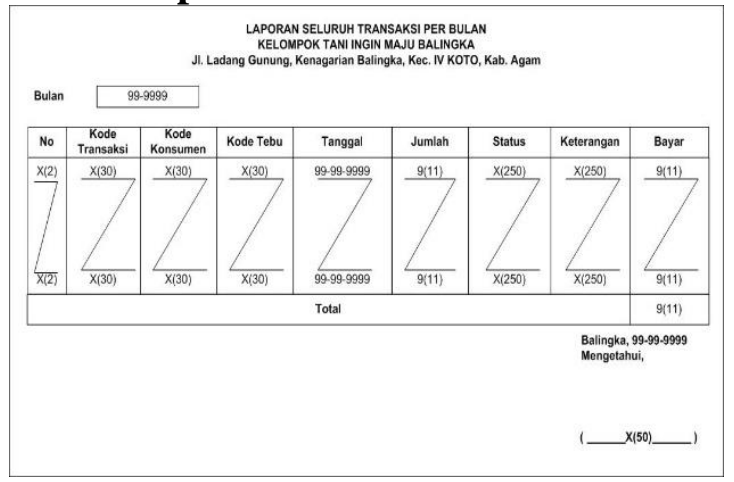

Gambar 12. Laporan Transaksi Per Bulan

\section{Laporan Transaksi Per Tahun}

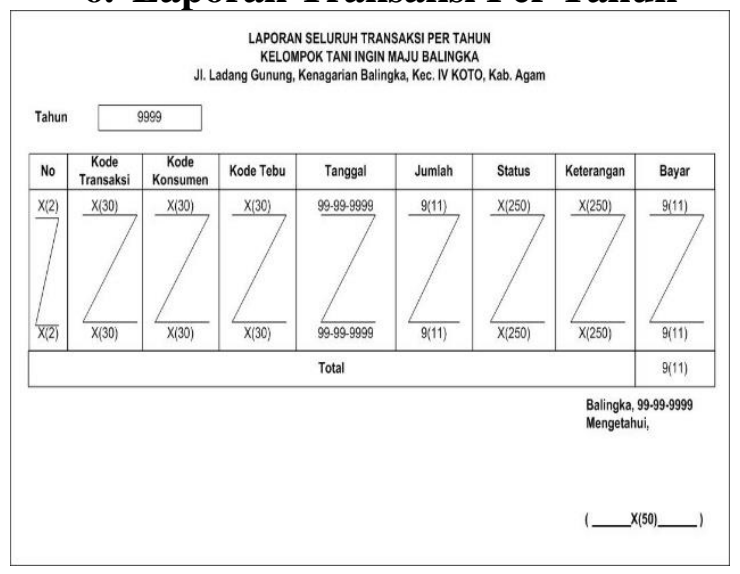

Gambar 13. Laporan Transaksi Per Tahun

7. Laporan Seluruh Transaksi

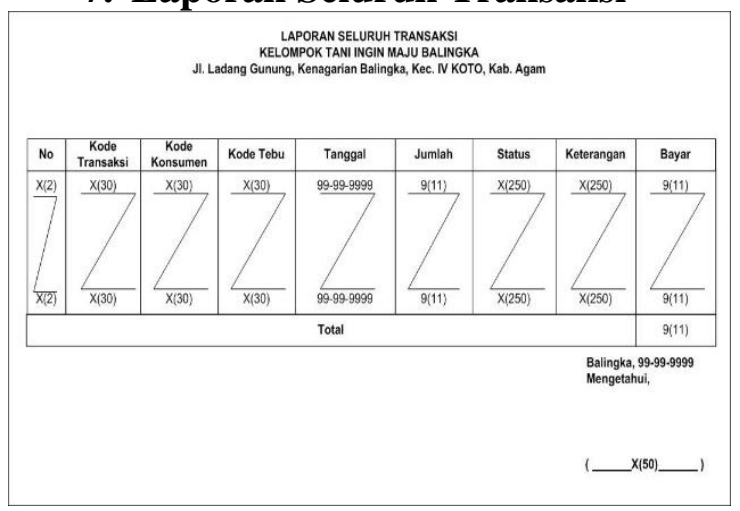

\section{Gambar 14. Laporan Seluruh Transaksi}

\section{Laporan Seluruh Pelunasan}

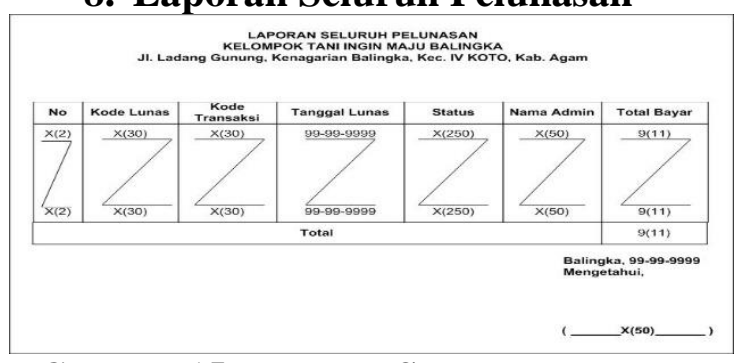

Gambar 15. Laporan Seluruh Pelunasan

\section{KESIMPULAN}

Dari pembahasan dan analisa pada babbab sebelumnya, dimana telah dijelaskan secara terinci mulai dari sistem yang diusulkan sampai terbentuknya sebuah rancangan system pada pengelolaan data, maka penulis menarik kesimpulan sebagai berikut :

1. Untuk mempermudah memantau transaksi pendistribusian dan data pelanggan yang terjadi pada badan kelompok tani ingin maju nagari Balingka.

2. Merancang sistem informasi pendistribusian gula tebu pada Kelompok Tani Ingin Maju Nagari Balingka.

\section{DAFTAR PUSTAKA}

Komputer, Wahana. 2010. Panduan Belajar MySQL. Database Server. Jakarta Selatan: mediakita

Kristanto, Andri. 2008. Perancangan Sistem Informasi dan Aplikasinya. Edisi Revisi. Yogyakarta: GAVA MEDIA

\section{MF, Mundzir. 2018. BUKU SAKTI PEMOGRAMAN WEB. YOGYAKART: Yogyakarta: START UP}

Nugroho, Bunafit. 2007. Latihan Membuat Aplikasi Web PHP dan MySQL dengan Dreamweaver. Edisi pertama. Yogyakarta: GAVA MEDIA 
Pratama, I Putu Agus Eka. 2014. Sistem Informasi dan Implementasinya. Bandung: INFORMATIKA

Tohari, Hamim. 2014. Analisis Serta Perancangan Sistem Informasi Melalui Pendekatan UML. 